\title{
LXVIII. Experiments proving the common nature of magnetism, cohesion, adhesion and viscosity
}

\author{
Sir Graves C. Haughton K.H. M.A. F.R.S.
}

To cite this article: Sir Graves C. Haughton K.H. M.A. F.R.S. (1847) LXVIII. Experiments proving the common nature of magnetism, cohesion, adhesion and viscosity, Philosophical Magazine Series 3, 30:203, 437-457, DOI: 10.1080/14786444708645425

To link to this article: http://dx.doi.org/10.1080/14786444708645425

曲 Published online: 30 Apr 2009.

Submit your article to this journal $\sqsubset \pi$

Џ Article views: 4

Q View related articles $\square$ 
most interesting cases of conversion of form are those in which the mind alone operates, and receives no aid either from inversion, shadow, or monocular vision. "If we take, as I have elsewhere remarked, one of the Intaglio moulds, used in making the bas-reliefs of that able artist Mr. Henning, and direct the eyes to it steadily, without noticing surrounding objects, we may coax ourselves into the belief that the Intaglio is actually a bas-relief. It is difficult at first to produce the deception, but a little practice never fails to accomplish it. We have succeeded in carrying this deception so far as to be able, by the eye alone, to raise a complete hollow mask of the human face into a projecting head. In order to do this we must exclude the vision of other objects; and also the margin or thickness of the cast. 'This experiment cannot fail to produce a very great degree of surprise in those who succeed in it; and it will, no doubt, be regarded by the sculptor (who can use it) as a great auxiliary in his art*."

From these observations it will be seen that the conversion of form, excepting in the normal case, depends upon various causes which are effective only under particular conditions; such as the depth of the hollow or the elevation of the relief, the distance of the object, the sharpness of vision, the use of one or both eyes, the inversion of the shadow, the nature of the object, and the means used by the mind itself to produce the illusion. In the normal case, however, where the cavity or convexity is shadowless, and upon an extended surface, and where inverted vision is used, the conversion of form depends solely on the illusion, which it is impossible to resist, that the side of the cavity or elevation next the eye is actually furthest from it—an illusion not produced by inversion, but by a false judgement respecting the position of the surface on which the form is placed.

St. Leonard's College, St. Andrews, May 4, 1844.

LXVIII. Experiments proving the common nature of Magnetism, Cohesion, Adhesion and Viscosity. By Sir Graves C. Haughton, K.H., M.A., F.R.S., Foreign Associate of the Institute of France, \&c. $\dagger$

\section{Part I.}

VARIOUS methods of experimenting have been employed of late years to extend the knowledge of magnetic phæthe substance of a film of sulphate of lime, described in the Edinburgh Transactions, vol. x. p. 35, they frequently appeared as elevations on the surface of the plate next the eye.

* Edinburgh Journal of Science, No. VIII. p. 109, Jan. 1826.

† Communicated by the Author. 
nomena, and to which we are indebted for many very valuable discoveries. That which I am now about to explain differs from all that have preceded it, and possesses at least the advantage of simplicity united to singular delicacy *.

It must have been clear to every one, that the phænomena observed by M. Arago in his well-known experiments made in the year 1824, when he caused a needle to oscillate over the surfaces of various substances, were due to the proximity of the needle to the body observed, as much as to the nature of the body itself; and the discovery of this distinguished natural philosopher was confirmed by Dr. Seebeck of Berlin, on making similar observations. Those $I$ have now to detail are entirely due to the same cause, carried to the extent of actual and forced contact.

I now proceed to explain the mode in which the experiments have been performed.

\section{Mode of operating.}

If the substance to be examined is flat, as a piece of glass, for instance, it should be set up on a very steady table, in a vertical position, and a magnetic needle, of which a description will be presently given, is to be placed on the point of a fine sewing-needle, about half an inch in height, which may be run through a slice of cork to answer as a support; but that which I myself employ has a flat brass foot about the size of a shilling, with the fine end of a sewing-needle fixed in the centre, and the brass foot is truncated close to the supporting needle, to enable it and the object to be brought close together for the purpose of observation. If a cork support is used, the sewing-needle should for the same reason be run through it near the edge.

When a minute object, such as a precious stone or any small fragment of metal, is to be examined, it should be placed on a piece of cork or any other suitable body, in such a position to the natural direction of the needle, that on the latter

* The general principle upon which these observations have been made was discovered so far back as the month of March 184I ; it was not however applied to ascertaining whether the various classes of substances were magnetic or not till the spring of 1845 , when nearly 140 substances were found to be magnetic, and a few measurements of the intensities were ob. tained, but it was at the commencement of 1846 that the greatest part of them were made. The remainder have been only recently completed; though these remarks were in such a state of forwardness as to lead to a hope of their being published in the summer of 1845 . Want of health has been the cause of these varions delays. 
being urged to it by a bar-magnet, its point will exactly touch some portion that is smooth and vertical. These conditions being strictly attended to, and the object under examination being placed about a quarter of an inch or so from the point of the magnetic needle, the pole of the bar-magnet that is of a contrary character to the point of the needle intended to touch the object, is to be approached with extreme gentleness and very slowly, so as to cause the least tremulous motion possible in the needle. When the bar-magnet is brought so as to cause the needle to press with a slight force against the substance examined, the former is to be kept in the same steady horizontal position, for at least ten or fifteen seconds after it has been observed that all tremor has ceased in the needle; upon which the bar-magnet may be withdrawn as slowly and as carefully as it was brought near. And this is the place to observe, that one great advantage of having the supporting pivot so short, and consequently the magnetic needle so low down, is that it enables the observer to allow the magnet to lie upon the table, and to advance and draw it back at pleasure, as well as to have its axis in the same horizontal plane as that in which the needle revolves; for should it be higher or lower than the latter, it would cause an inclination, and a consequent displacement of the needle, from gravitation the moment the bar was withdrawn, that might interfere with the success of the experiment. If all the conditions just described have been attended to, the needle will be found to have attached itself firmly to the glass, copper, or other body operated upon, and will in many cases so remain any indefinite time, if not disturbed. But it should be well-remarked that time must generally be given to the magnetic needle to settle, and thereby coerce the substance to which it is to attach itself. This is an essential condition in most cases. The slightest movement in the room, even the motion of the air from the impulsion given by the breath of the observer, are to be carefully avoided in the nicer experiments. Any vibration in the house also will, in most cases, from the extreme delicacy of the operation, cause a failure. Some time, too, will in all probability elapse before the experimenter will have acquired the dexterity necessary to the success of the difficult cases, and he must be careful that the point of the magnetic needle does not catch itself against the object under examination when it is rough; and there is also great danger of its becoming jammed when it approaches an angle of $90^{\circ}$ with the magnetic meridian. To prevent such a consequence, the object should be so placed, when the amplitude is large, that only the side of the point of the magnetic needle may rest 
against it, Either pole of the needle may be used, and the bar-magnet may be made to influence it either by attraction or repulsion, as is most convenient for the observation. The operator will likewise find it an advantage to use a low seat, as he will by that means be able to have his eye in the same level as the object examined as often as it may be necessary, particularly when minute objects are observed.

All that has just been said merely regards the mode of avoiding a failure; but if it is desired to measure the relative magnetic intensities of the substances under examination, then a graduated disc is to be employed, which may be placed under the supporting needle, its $N$. and $S$. being in the line of the magnetic meridian; but a very convenient substitute for these two will be found in detaching the bottom of one of the compass-boxes, of which I shall immediately speak, covered with its engraving of the rhombs and degrees, and cutting away so much of it as might interfere with the approximation of the different bodies. The nearer the needle can be brought to $90^{\circ}$ by the attraction or repulsion of the bar-magnet, the greater is to be considered the magnetic intensity of the object, which is to be shifted after each measurement so as to increase the angle of amplitude till it is found that the needle will no longer attach itself, which consequently gives the limit of its magnetic intensity, This being an exhausting and tentative process, renders such measurements extremely tedious in many cases, and yet it cannot be remedied; for, owing to the time lost in waiting for the oscillations of the needle to cease, as well as for it to connect itself with the substance, and in the various adjustments of the latter, much time is expended; added to which, the experiment must be often repeated in difficult cases, to be quite sure that a failure has really arisen, from a want of attractive affinity between the needle and substance. Nearly an hour has been consumed in an experiment where much attention and delicacy of manipulation were required.

Great care of course must be taken not to confound effects purely electric with those that are magnetic. To prevent such a possibility of error, it is only necessary to breathe upon a suspected substance, which will effectually remove all free electricity. Thus Iceland spar, which cannot be touched with the fingers without becoming electric and remaining so for days, may in the space of a few seconds be rendered fit for examination, as the humidity of the breath quickly evaporates and carries off the superabundant electricity.

It is well-warthy of remark, as showing how much time is necessary, not merely for the exhibition of magnetic attraction 
by some substances, but also for the loss of this quality, that in many cases where the needle was with difficulty made to attach itself, on contact being broken a fresh connexion was produced with the greatest ease, if only a short delay had taken place, and no change whatever had been made in the position of the object. Time, too, was still more necessary to the success of the experiments when the angles were to be measured; for it not unfrequently happened that, when I had supposed the greatest amplitude had been attained, on maintaining the forced commexion for a few minutes with an enlarged angle, a firm connexion took place; thus throwing a doubt upon the measures I had previously noted as the highest attainable in other substances. Such measures, therefore, even in any case, can only be considered as approximative, as greater deviations may possibly be yet obtained by myself or other observers. Thus in the case of a spark of diamond, I was able to increase the angular distance from $42^{\circ}$ to $65^{\circ}$. So likewise in the case of quartz, it rose gradually from $45^{\circ}$ to $90^{\circ}$. Now when it is considered that the attachment of the needle takes place generally with the greatest readiness when the angle of deviation is small, say $10^{\circ}$ or $15^{\circ}$, owing to its limited deviation from the meridian in such cases, it can leave but little doubt that this peculiarity arises from the slow effect of magnetic propagation in the substance examined, in which, to use language that has become familiar in describing magnetic phænomena, saturation takes place but slowly.

The foregoing facts entirely accord with the remark made by Sir John Herschel and Mr. Babbage, when in 1825 they varied the experiments of M. Arago. A remarkable confirmation of this peculiarity was exhibited by chromium, which was entered, after many trials with a magnetic needle, as a failure, yet on repeating the experiment, and allowing a long time for the needle to operate, the measurements rose successively, according to the notes taken on the occasion, as follows: $20^{\circ}, 25^{\circ}, 90^{\circ}, 40^{\circ}, 45^{\circ}, 49^{\circ}, 55^{\circ}, 70^{\circ}, 90^{\circ}$. The notes on the subject having been overlooked, a fresh attempt at measurement, after the lapse of more than a year, was recently made, when it was again entered as a failure, as there was not the least tendency to a connexion between the needle and the chromium after the ordinary time given to other difficult substances.

On reflecting on the necessity of time being given to develope the magnetism of some substances, and remembering that the needle, which was the active agent in its production, did not weigh four grains, and that the parts of the needle and the substance in contact were merely two minute points, it struck 


\section{Sir G. C. Haughton on the Common Nature of}

me that the magnetism might be much increased by keeping it in close contact for a short time with a more powerful magnet. The result fully justified this anticipation, and the attractive affinity between the needle and the substance was immediately augmented; but generally in those cases where no attraction had been already discovered, none made its appearance by the additional magnetic influence to which it was subjected. Want of health and time prevented me from establishing more than the general character of these last facts, but I shall have to speak more fuliy of the particular cases tried as I proceed.

Among the few substances placed in contact with the barmagnet for the purpose of increasing their magnetic energy, the following seem to be totally uninfluenced by its presence, viz. copper, lead, marble, selenite, alum and pure lac.

The following experiment will show how strong the connexion often is that takes place between the needle and nonferruginous substances. A magnet having been brought vertically over the needle contained in a small box-compass, which was screened by a piece of crown-glass, the needle attached itself instantly, or, to speak more exactly, per saltum, so firmly to the glass, that the box might be pushed backwards and forwards from one end of the chimney-piece on which it lay to the other, without contact being broken; and in this state it continued for six days, though the door of the room was often shut with considerable force; and the connexion was at last only broken by the box having inadvertently received a shock from the hand. The contact was occasionally renewed by the same means, sometimes for two or three days, and always continued till broken at pleasure. This experiment will not succeed if the pivot of suspension is either too high or too low; and the needle must be of the pointed kind.

It is proper to describe here a very useful electrometer which I employed to ascertain whether substances exhibit any electrical effects. It is of extreme simplicity, and is not merely much more sensitive than that employed by Haïy, but even more so than the most delicate gold-leaf electrometer. It consists of a magnetic needle five-eighths of an inch in length, with an agate cap. Upon each end of the needle a piece of oaten straw, one inch in length and about one-thirtieth of an inch in diameter, is fixed. When this part of the system is placed, as in the former case, on the point of a sewingneedle with a brass stand, the instrument is complete. It has an additional advantage over that of Haüy, that, owing to the 
slight magnetism of the needle, the points of which are inserted in the straws, it preserves a definite position, without the slight magnetism of the needle apparently interfering with its sensibility. It has likewise the advantage of being easily set up or dismounted to protect it from injury, and is capable of being contained in a very small box. I ought to remark likewise that it is so susceptible, that if unprotected by a screen it is kept in a sort of perpetual movement, by the otherwise inappreciable currents of air in the room.

\section{Proper forms of the needles and magnets.}

After the trial of needles of various forms and lengths, I have found none that answer so well as those which are employed in the compasses of commerce, set in mahogany boxes two inches square, and to which I have already alluded. The needles in these boxes are an inch and a half long, very slender and pointed, weighing about three grains and a half. Their caps are of brass, which in this case is an advantage; for needles with those of agate are much too tremulous from their great sensibility, and the experiment will be almost sure to fail if the point of the needle slips in the least from the spot where it first settles, the circumference of its action being as limited as the part of the point of the needle actually in contact. Long needles, therefore, owing to their great oscillations, are particularly unfit for these experiments; while, on the contrary, I have succeeded extremely well with a needle not more than five-eighths of an inch long.

The preceding directions sinıply concern the kind of magnetic needle that is to be employed; but it is, as I have said, by the aid of a bar-magnet that the needle is made to attach itself to non-ferruginous bodies; for by no other means could it be caused to approximate itself by a slow, steady, and gentle movement, and be left without disturbance when the motive agent is withdrawn, a condition upon which the success of the experiment entirely depends in the cases of low intensity; but for those of higher attraction, I shall presently show a simpler mode of attaining the same end without a magnet. The bar-magnet which I use is very convenient; it is six inches and a half long, three-quarters of an inch wide, and rather better than a quarter of an inch thick. If the magnet is long, it is managed with difficulty; and if small, it requires to be brought very near the object, and there.is consequently danger of disturbing the position of the needle when the magnet is withdrawn, which had better likewise be wrapt in soft paper, to enable it to be laid down on the table without causing a jar 


\subsection{Sir G. C. Haughton on the Common Nature of}

or shock. I now proceed to an important step in these discoveries.

On the relative dynamic values of the degrees of the compass, and on the cause of the needle resting in the magnetic meridian.

Shortly after I had begun to measure the angles of deviation, I saw that it was a matter of the first necessity to ascertain whether the degrees of the compass after $90^{\circ}$ increased in strength, or went on diminishing in some given ratio, as it appeared to me that the connexions were made with increased facility in proportion as the $\mathrm{N}$. pole of the needle approached nearer to $180^{\circ}$. For the purpose of settling this question, I made a number of most careful measurements, after drawing proper lines upon a sheet of paper, which all crossed one another in a common centre, by ascertaining the distances at different azimuths at which a bar-magnet, placed with its axis directed to the centre of a magnetic compass-needle (the pivot of suspension of which was exactly over the common centre of the lines of which $I$ have spoken), eaused the needle to assume a position in which its axis was in the same line with that of the magnet, I found that these points of distance form a peculiar curve, which was nearest to the axis of the magnet at the east and west azimuths, and receded from it as it advanced to the north and south; and was twice the distance from it at the north that it was at the south azimuth. Such is the sum total of the results which I communicated to the Royal Society in June 1846, and of which a short account has been given in the Abstracts of the Papers read before the Society, and republished in this Journal for last November*. It since however occurred to me, that the longest distance from the east and west azimuths would be better ascertained by operating by the means of repulsion than by attraction, as I had done; for it is evident that repulsion will sooner discover a minute deviation of the needle when in its natural position at $\mathbf{N}$. than can be effected by attraction, because if the axis of the bar-magnet deviates in the slightest degree from the line, a false value will be obtained; and there always therefore remains a doubt in proceeding by attraction, respecting the point where the reciprocal action of the needle and the magnet ceases, in consequence of the identity of their axis. Now in proceeding by repulsion, the reverse takes place; and the minutest difference, except so far as the friction of the needle on its pivot is concerned, is immediately detected. I was surprised therefore to find that where I bad only been able to discover a devia-

$$
\text { * Vol. xxix. p. } 405 .
$$


tion at eight inches distance, owing to the minute quantities concerned, I could obtain a deviation at sixty inches, after which all effect ceased. As the distance was exactly four inches from the centre when the north end of the needle was drawn to $180^{\circ}$ by the bar-magnet, and as there must be some definite ratio between the two distances thus obtained, I assume that the true length of the greater azimuth is sixty-four inches, and that the four inches not discovered in the measurement resulted from the friction of the needle on its pivot, though it was an extremely delicate instrument that had been made by M. Pixii. Instead therefore of the greater distance being merely the duplicate length of the shorter one, it is related to it as its cube.

The reason of this disproportion of the needle when in its natural position, from that which is discovered when it is forced round to the opposite pole, may, I think, be found, when it is remembered that, as the earth is either per se or by induction a magnet, the latitude in which the experiment has been made being at such a distance from the magnetic equator, there can be no longer an equality in the effects. It would be therefore a question, I think, not devoid of interest, to ascertain whether such a disproportion exists at the magnetic equator.

I will now describe the means by which a long line was obtained, upon the exactness of which the accuracy of the observation necessarily depended. A white thread of fine cotton, weighted at each end with lead, was laid over a long and steady table, and the weights being allowed to hang down, a perfectly right line was instantly obtained, which had only to be adjusted so as to agree with the magnetic meridian.

The length of the azimuths obtained in the lines N., E. and S. being respectively $64,2,4$, it follows that by the law of the inverse square of the distance they are related to one another in the proportion of $1 \cdot 1024$ and 256 , and that consequently every degree rises gradually from $\mathrm{N}$. or $0^{\circ}$, till at $\mathrm{E}$. or $90^{\circ}$ its strength is 1024, after which there is a rapid decrease up to $180^{\circ}$; and it may therefore be practically assumed, to save circumlocution, that at $175^{\circ}$ its proportional strength is $256^{\circ}$, or only one-fourth the strength it has at $90^{\circ}$, that being the true proportion as it reaches $\mathrm{S}$. or $180^{\circ}$, where the needle is necessarily in a state of equilibrium by its balanced attraction to the west; but all this will be much more evident by a reference to the curve itself, which is preserved in the form that was laid before the Royal Society, as it would be inconvenient to represent on paper the due proportion from the centre to $\mathrm{N}$. In fact, for all practical purposes, the new correction is 


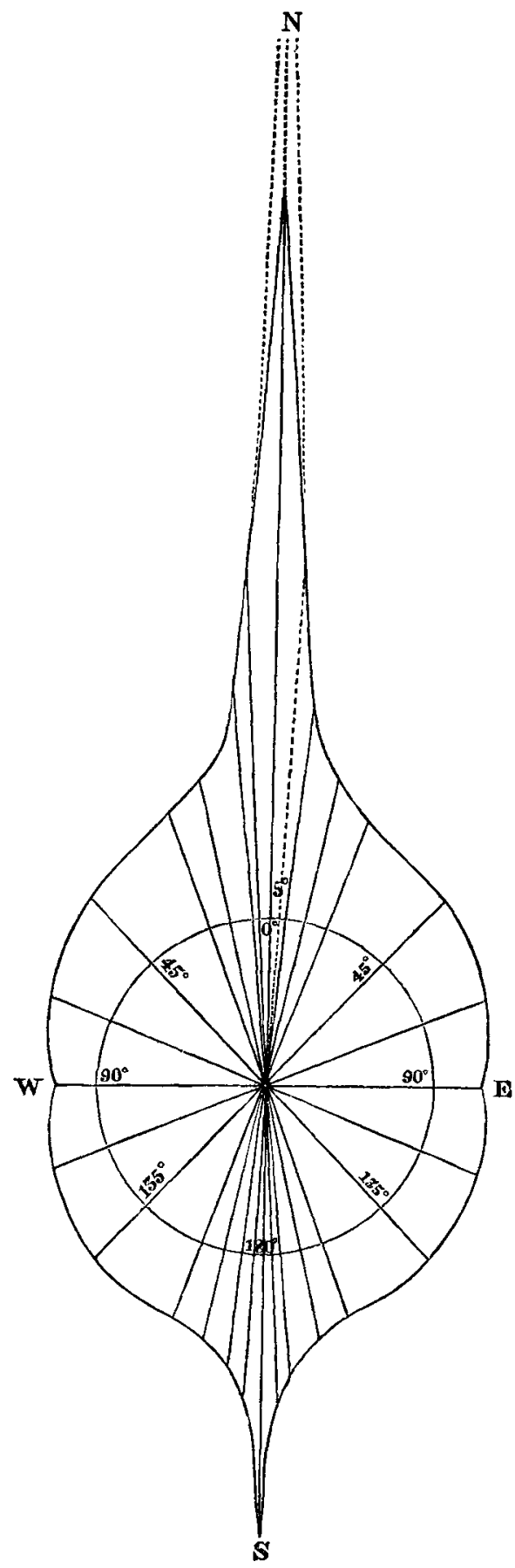

The true proportions of the curve, from the centre to E. or W., is 1, to $S .2$, and to $N .16$; but as the distance from the centre to $N$. could not be represented conveniently on paper, the dotted lines on each side of the line N. must be supposed to be elongated to that extent. 
of no consequence, as anything lower than the azimuth line that passes through $5^{\circ}$, I have found to be as low as can be ever required for any useful measurement; and it will be seen that by the dotted line I have drawn passing through it, and the dotted lines that are intended to represent the correction of the curve, that azimuth remains unaffected. Measured by a rule, the proportion of the azimuth line passing through $90^{\circ}$ is as 1 to 2 with that passing through 5 . Now by the inverse ratio of the distance, it has only one-fourth of the strength at $5^{\circ}$ that it has at $90^{\circ}$; and practically, therefore, is the same in strength at $5^{\circ}$ as it is at $175^{\circ}$. Hence $90^{\circ}$ may be considered as a middle point, from which the degrees dininish by equal decrements to $5^{\circ}$ and $175^{\circ}$; and it will be seen by a reference to the curve, that the azimuth lines cutting $45^{\circ}$ and $135^{\circ}$ are essentially the same in length. The ascertainment of the true strength of the degrees from $90^{\circ}$ to $180^{\circ}$ was a necessary desideratum, which has led to the unexpected discovery that the position of the magnetic needle north and south is the effect of equilibrium arising from equal repulsions from east and west; and that so far from there being any attraction at N. and S., they are just the two points where the needle is in the greatest state of freedom; and that in the case of a needle of low magnetic power, the mere resistance caused by friction on its pivot, will be sufficient to prevent its taking up its true position in the line of the magnetic meridian. These facts prove that the movement of the needle from $90^{\circ}$ to zero depends upon repulsion, commencing at $90^{\circ}$, and diminishing gradually till it stands in equilibrium at zero; and that the return of the needle to $90^{\circ}$, when the north end is brought to $180^{\circ}$, is the result of an attraction that increases up to $90^{\circ}$, when the repulsion commences.

The mathematical expression of these results is that-

The value of every degree of the compass is inversely as the square of the length of the ordinate or co-ordinate passing through it, the abscissa being considered as zero.

The general principle of the values of the various degrees of the compass obtained by the preceding system of azimuths, was further verified by the following method:-

A bar-magnet $12 \frac{7}{8}$ inches long, was properly suspended by silk, free from torsion, and the $N$. pole being brought round to the south, was allowed to return back by the east. The following is the mean of eight observations, made with great care, and which only slightly differed from one another. The bar required $11 \frac{1}{2}$ seconds to complete its return from $130^{\circ}$ to $135^{\circ}$. When made to start again from $135^{\circ}$ to $90^{\circ}$ it occupied six seconds; and when allowed to depart again from $90^{\circ}$ 


\section{Sir G. C. Haughton on the Common Nature of}

to $45^{\circ}$, the time occupied was $5 \frac{1}{2}$ seconds; while its return from $45^{\circ}$ to $0^{\circ}$, after being again left to itself, took $6 \frac{7}{8}$ seconds.

It might be supposed, a priori, that the north end of the bar-magnet when brought to the south and left to itself would be repelled with violence; but so far from this, as seems to be the case when small needles are observed, its movement is extremely slow, and there is a loss of a second or two before it acquires the gradually augmenting momentum that is to carry it back: a momentum indeed which increases so rapidly that though the bar consumed $11 \frac{1}{\mathrm{~g}}$ seconds to carry it back from $180^{\circ}$ to $135^{\circ}$, it only required $15 \frac{1}{8}$ seconds to carry it from $165^{\circ}$ to $0^{\circ}$, and of this time $13 \frac{1}{8}$ seconds were occupied in reaching $45^{\circ}$, after which the remaining $45^{\circ}$ were completed in 2 seconds; yet the bar required $6 \frac{7}{8}$ seconds to return from $45^{\circ}$ to $0^{\circ}$, when it had not the benefit acquired by the preceding momentum. As a further proof how much the slowness of the movement of the bar increases near $0^{\circ}$, when not assisted by previous momentum, $6 \frac{3}{8}$ seconds was the space of time requisite to carry the bar from $5^{\circ}$ to $0^{\circ}$, yet when it had the advantage of the momentum acquired between $10^{\circ}$ and $5^{\circ}$; it completed the whole in $\frac{1}{4}$ second less time, that is the space from $10^{\circ}$ to $0^{\circ}$ in $6 \frac{1}{4}$ seconds, while it has just been seen that it required only 2 seconds to carry it from $45^{\circ}$ to $0^{\circ}$, when it had the advantage of the previous momentum acquired by setting off from $165^{\circ}$.

There was a peculiarity in the return movement of the magnetio bar which is worthy of attention. When the north end moved from $180^{\circ}$ to $13 \tilde{\sigma}^{\circ}$, it required, as has just been seen, $11 \frac{1}{2}$ seconds to complete the amplitude, while it only took $6 \frac{7}{8}$ seconds to traverse over the parallel amplitude from $45^{\circ}$ to $0^{\circ}$. The reason of this difference is, that in the first case its momentum is in an increasing ratio, and the force that is to move it has gradually to augment, while from $45^{\circ}$ it sets off with a strong momentum which it retains till it reaches $0^{\circ}$. What the nature is of this force which goes on increasing on the return of the bar up to $90^{\circ}$, and from that point continues decreasing down to $0^{\circ}$, is a question of much importance in the theory of terrestrial magnetism. It is evidently one at right angles to the natural position of the needle, and seems to be caused by a principle identical with that of the conjunctive wire of the pile, and would strongly tend to confirm Ampere's theory of electric currents from east to west, if the sipposition of the efficiency of these were not opposed by considerations to which I may return on a future oceasion.

While upon this point it will be interesting to see the relative times occupied by the needle when drawn back to $175^{\circ}$, 
in its return to $0^{\circ}$, measured through regular divisions of the compass. On account of the difficulty of starting the needle from $180^{\circ}$ when in equilibrio, the measurement only began from $175^{\circ}$.

To simplify the expression of the results, and save the use of decimals, the signs plus $(+)$ and minus (-) are used to denote time in excess and paucity, which in the mean of eight observations were too insignificant to be otherwise brought in.

\begin{tabular}{|c|c|c|}
\hline Amplitudes. & Mean. & Decrements on each side of $90^{\circ}$ \\
\hline 15 to 0 & 6 & $2 \frac{5}{8}$ \\
\hline 30 to 15 & 4 & $\frac{7}{8}$ \\
\hline 45 to 30 & $3 \frac{1}{8}$ & $\frac{3}{8}+$ \\
\hline 60 to 45 & $2 \frac{3}{4}$ & Repulsion. \\
\hline 75 to 60 & $2 \frac{3}{8}$ & $\frac{1}{8}$ \\
\hline 90 to 75 & $2 \frac{1}{4}$ & $0 J$ \\
\hline 105 to 90 & 23 & 0 \\
\hline 120 to 105 & $2 \frac{5}{8}$ & $\frac{1}{8}+$ \\
\hline 135 to 120 & $3 \frac{1}{4}$ & Attraction. \\
\hline 150 to 135 & 4 & $\frac{3}{3}+$ \\
\hline 165 to 150 & $6 \frac{7}{10}$ & $\mathcal{2}_{\overline{1} \frac{7}{6}}$ \\
\hline 175 to 165 & 9 & $2_{19} \mathrm{~J}$ \\
\hline
\end{tabular}

The mode $I$ have described of measuring the insensible magnetic attractions of non-ferruginous bodies, has the rare advantage of the most perfect delicacy and precision in all angles up to $90^{\circ}$, but from thence to the moment when sensible attraction commences, there is considerable vagueness, as far as relative intensities are concerned. Where perfect repulsion occurs it is distinctly indicated by the impossibility of forming a connexion; but it is likewise evident that in many cases a low degree of repulsion to the magnetic needle is overcome by giving time for magnetic propagation, or by keeping the substance operated upon in contact with a powerful magnet. Where a body is very light, as cork or charcoal, the failure must be attributed to their want of density, for the part of the needle which comes in contact with the bodies is but a minute point, yet the molecules which compose the cork or charcoal in that spot, must stand at such a distance from one another as to render their magnetism ineffective, and therefore inappreciable.

The delicacy of this mode of measurement is sufficiently attested by its having been applied with equal success to a Phil. Mag. S. 3. Vol.30. No. 203. June 1847. $2 \mathrm{H}$ 
hair of the human head, and to a spark of diamond; and the accuracy attained may be judged of by the fact, that the same hair having been measured a year afterwards, was found, without any remembrance of the previous measurement, to be what it was before, namely $80^{\circ}$. A specimen from another head which only gave $76^{\circ}$ was lost, and the measurement could not be verified, but another hair from the same head being tried it was found to be $82^{\circ}$, a difference which may be accounted for by supposing that all the hairs on the same head are not possessed of equal magnetic intensity at the same moment of time, or by a change in the state of the health of the individual. The measurements may be relied upon as never in excess, though from causes of disturbance, such as the vibration of the house, \&c., they must occasionally be capable of being pushed further. No pains however have been spared to obtain the utmost degree of accuracy. Those who shall undertake to repeat these experiments will be best aware of the extreme difficulty of the subject.

\section{Of the marks of indication.}

Substances not followed by any numerals have been ascertained to be magnetic, but have not been measured.

A o implies that no attraction could be discovered.

The sign + marks that the measurement could be carried further.

The sign $\times$ after $90^{\circ}$ is intended to show that the magnetism is still stronger than that of the highest case of + .

The double sign of $x$ (that is $x \times$ ) is employed to show that the connexion has been effected by the delicate employment of the finger instead of the magnet; but that the inagnetic intensity of the substance is still not sufficient to attract the needle, whether ferruginous or non-ferruginous of itself. This is the "simpler mode" already alluded to.

A marks such substances as attract the needle, though at short distances.

The magnetic needle was made to connect itself with all the undermentioned substances not followed by 0 , which are arranged according to their classes; and the measurements of such as I had time to ascertain are inserted after each.

1 st Class.

\begin{tabular}{|c|c|c|}
\hline Gold (pure) ......... 90 & Lead .................90 90 & Cobalt \\
\hline Do. (18 carats)..... 90 & Zinc .................99 90 & Plumbago ............ 0 \\
\hline Silver (pure)......... 90 & Copper .............. 90- & Iodine $. . . \ldots \ldots, \ldots \ldots$ A \\
\hline Do. $(\operatorname{coin}) \ldots \ldots \ldots \ldots 90+$ & Mercury & Arsenic .... \\
\hline Platinum ,......... 65 & Antimony ... & Brass . \\
\hline Palladium ........... 68 & Bismuth .......... 51 & German silver \\
\hline Cadmium ........... 90 & Chromium............ 90 & Bell-metal............ 90 \\
\hline 90 & Manganese ...... & \\
\hline
\end{tabular}


I have already spoken of the manner of raising the magnetic intensity of various substances, by keeping them in close contact with a bar-magnet for a short time. The following metals had their magnetic intensities slightly raised by this means :- -

\section{Platinum, from $65^{\circ}$ to $90^{\circ}$; Antimony, from $66^{\circ}$ to $90^{\circ}$; Bismuth, from $45^{\circ}$ to $80^{\circ}$.}

It is very remarkable that it is not of the least consequence whether the substance is kept in juxtaposition with the N. or $S$. end of the magnet, for the result will be just the same in either case, and the N. or S. end of the needle may be made to attach itself with equal indifference to the part of the substance that has been so excited. Whether this proceeds from a want of polarity in ferruginous magnetism, or from the molecules of the substances having been rendered more obedient to the coercive energy of the needle, it is difficult to say. As the magnetism still remains, after such influence, of the insensible kind, it is clear that they cannot penetrate to any depth, and this may be the reason why no polarity can be formally proved. The possible existence of polarity is countenanced by the fact that the magnetism is capable of being heightened, and by the analogy of the connexion that takes place between two similar poles of magnets when brought forcibly into contact, as well as by what takes place with arsenic. The magnetism which is found to exist in all matter, and that to a degree which has never been anticipated, would be of tremendous operation in nature if it were not like or identical with cohesive affinity, and consequently acting only at distances that may be considered as insensible. In this respect it contrasts strongly with the power of gravitation, and with that even of the magnetism of steel.

The effects that take place by keeping substances in contact with a magnet cannot be attributed to induction, as they continue for a longer or shorter space of time after separation.

The measurements of the first class of substances speak so clearly for themselves, that there would be but little occasion for any remarks upon the greatest portion of them, if it were not for the contrast in which some of them stand to the important results obtained by Dr. Faraday, when he operated with a very powerful electro-magnet. From the effects he observed he divides all metals into two classes, namely, magnetic and diamagnetic, according as they showed attraction or repulsion; the first of these states being indicated by the cylinder placing itself in the line of the axis of the magnet, and 


\section{Sir G. C. Haughton on the Common Nature of}

the other, on its taking up a position at right angles to the same axis. Now it is not a little remarkable that platinum and palladium, which he selects as magnetic, exhibit, it will be seen, a lower state of attraction than cadmium, copper, gold, mercury, and silver, and that these, in common with antimony, bismuth, lead, tin, and zinc, in which he found repulsion, all exhibit attraction, according to the present form of experiment, and some in a very strong degree.

The case of antimony and bismuth is deserving of attention, for by a method somewhat analogous to the present one, the late $M$. Lebaillif found that they exhibited repulsion; though in his experiments the bodies were not forced into contact, and therefore their occult properties were not elicited. In these two instances, as is the case with all bodies of low attractive power, the connexion was formed with some difficulty; but as it was repeated on many occasions at different intervals of time, and even within a day of these remarks, not the slightest doubt can exist on the point. But I shall have to return to this subject again.

Another fact resulting from the two modes of experimenting employed by Dr. Faraday and myself, is that the connexion could be formed on any side or end of the substance, and that form had no influence upon the result. Indeed this was to be expected, as the transverse position which the substances assumed in his hands lesulted from their shape, as every oblong body under repulsion must necessarily place itself at right angles to the resultant of forces, with a facility proportioned to its length and slenderness. Where the shape of the substance examined would permit of it, the end has of late always been selected in preference to the side, with a view to ascertaining this point; and this was particularly the case with the antimony and bismuth, which were in bar, and had been cut across.

I have introduced iodine into the class of metals and metalloids, as its semi-metallic lustre seemed to justify it, and because I found that it attracts the magnet of itself; but it shows no polarity. All that is necessary is to hold a scale of this body against the point of the magnetic needle, when, on drawing it back, the needle will remain connected with it for $40^{\circ}$ or $50^{\circ}$ of the compass. A piece of arsenic too, which showed very low magnetic intensity $\left(15^{\circ}\right)$, acquired a similar power, but in a higher degree, after it had been for a short time in close juxtaposition with the end of a bar-magnet; but it was remarkable that this power only appeared on the flat side of the arsenic where it had pressed against the crucible in which it was melted, the other broken parts of the sides 
being only raised by the same process to $85^{\circ}$. I attribute this peculiarity to the greater number of points that are brought in contact with the magnet where the surface is flat. The character of the magnetism thus acquired is entirely the same as that of steel, attracting and repelling in the same manner, but comparatively in a very low degree, and consequently quite superficial. If bronght quite close to that end of the needle for which it exhibits repulsion, it will, like a magnet, in consequence of the proximity, attract it. It lost its magnetic power in the course of a few weeks, but it has since been renewed with the same facility as before.

It appeared to me that the needles got out of order, for a short space of time, by their contact with the iodine and arsenic; but upon this point I cannot at the present moment speak positively. Certain it is that they became quite paralysed on two or three occasions, but were restored by having recourse to the touch, and subsequently by only letting them lie quiet an hour or two. I suspected the same effect to have taken place once or twice, after keeping them in contact with antimony, but at other times I could assign no cause for the change.

All the specimens of brass I have examined are very magnetic, and may have that property considerably increased by putting them in contact with a magnet. One specimenl, which is a bar, causes attraction at one end, but the repulsion which existed at the other has disappeared. The former state appears to continue unchanged, at least I have seen no difference in the course of a year. Bell-metal has very low magnetic powers; so much so indeed that I despaired of making the needle connect itself with it; nor was this object effected till they had both been kept in connexion for some time, and even then there was every symptom that this was attained only by overcoming a natural repulsion, as in the case of chromium, of which I have already spoken. No change seemed to be effected by keeping it in contact with a magnet. German silver is magnetic, and if brought within about the eighth of an inch of the needle will attract it. But the specimen I had, seemed by its colour to contain an unusual proportion of copper, or otherwise it might have proved more magnetic. No increase of magnetism resulted from connection with a larger magnet. Cobalt and manganese, as is known, attract. The needle clung at once to a globule of mercury, against which it had been urged by the magnet.

All the rarer substances, including pure gold, in the preceding class, I believe to be chemically pure, as they were obtained from Messrs. Boyveau and Pelletier, and M. Ber- 


\section{Sir G. C. Haughton on the Common Nature of}

hemot of this city (Paris), who considered them as such; but the tin and lead were taken from the ordinary specimens of commerce, and if the supposition which accounted for the magnetism of non-ferruginous bodies by their containing minute portions of iron, had any foundation, it would have been apparent in these two substances; yet it will be seen that the magnetism of both shows nothing very remarkable, and that the tin exhibits the same degree of attraction as the specimen of cadmium which I believe to be chemically pure, and these two will be found, nearly in all circumstances, to exhibit as remarkable a conformity magnetically as they are known to do chemically. When I show, however, the mutual attractions of non-ferruginous bodies, it will be seen that the notion of Coulomb, and other experimenters posterior to him, cannot be accepted as accounting for the results they observed.

\section{2nd Class.

Selenium ...... $10^{\circ}$ | Sulphur $28^{\circ}$

Selenium and sulphur both exhibit very low intensities with the magnetic needle, and even these are obtained with so much difficulty as to demonstrate that they are forced states. I have paid particular attention to these two singular substances, and have found that they resemble one another as much by their magnetic properties as by those that are chemical. I will here anticipate the branch of this inquiry which is to follow, by stating that they are remarkable in nearly agreeing in their affinities for the metals, but particularly for gold. They, however, show not the slightest attraction for one another, and therefore must be considered as mutually repulsive. I have invariably found that where there is a chemical resemblance there is likewise similarity in magnetic properties, and these two substances maintain their resemblance in the same way as tin and cadmium, which only exhibit a difference of nature with respect to arsenic; but everything regarding this last body seems anomalous, which, like sulphur, has no affinity for selenium. Contact with the magnet appears to elevate their power of sttraction, at least this was the case, as will be seen hereafter, when they were tested with brass.

3rd Class.

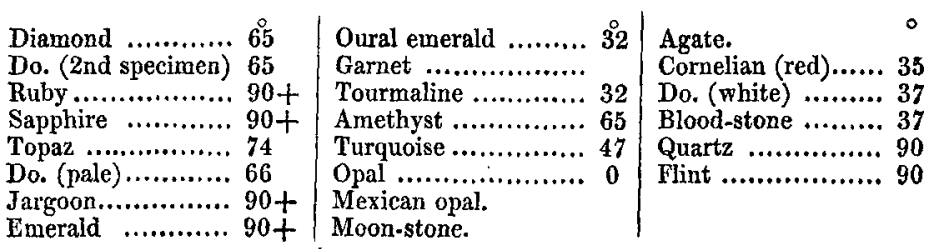


The present class exhibits many various degrees of attraction for the magnetic needle, but the ruby, the emerald, the sapphire and the jargoon, it will be seen, stand high in rank for this property, while tourmaline and oural emerald are but low. The diamond was the only one of these precious stones that was placed in contact with the magnet, and it was found to have its energy raised by the connexion. Though the diamond does not exhibit much attraction for the magnetic needle, it will be seen hereafter that this is compensated for by its affinity for copper, platinum and glass of every kind; and it will be generally found that what is of difficult connection with the magnetic needle is remarkably the reverse with glass, and they may respectively be placed at the head of a binary division of all substances; and what makes the fact the more remarkable, is that the attractive properties of glass are heightened in a very sensible degree by its remaining in contact with the magnet. Glass has a striking affinity for cornelian, red and white, and for blood-stone, while a connexion between the magnetic needle and these stones is formed with extreme difficulty.

It might have been expected that flint would have shown much resemblance to quartz in its attraction for the magnetic needle, but the connexion was always formed with great difficulty, and on many occasions, though it appears as high as $90^{\circ}$, it could not be raised above $20^{\circ}$ in some particular spe.cimens, and many were tried. Yet the needle attached itself with great facility at $40^{\circ}$ and $50^{\circ}$ to quartz, and finally reached $90^{\circ}$, but not by any forcing process: that measure however is still its ultimate limit. Flint has a decided repugnance for the magnetic needle, but still the magnet can overcome it, and a refractory specimen was raised by this means from $20^{\circ}$ up to $40^{\circ}$.

\section{4th Class.}

\begin{tabular}{|c|c|c|}
\hline 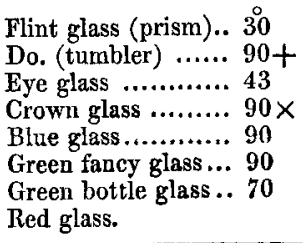 & 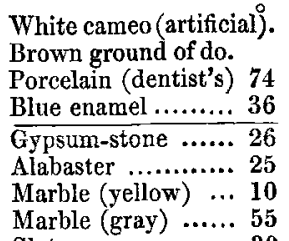 & $\begin{array}{l}\text { Felspar ............ } 10 \\
\text { Selenite............ } 15 \\
\text { Talc ............. } 60 \\
\text { Sulphate of iron.. } 48 \\
\text { Protosulphate of }\end{array}$ \\
\hline French).. 90 & $\begin{array}{l}\text { Red chalk. } \\
\text { White chalk. } \\
\text { Crystallized tin...... } 0 \\
\text { Iceland spar......... } 90\end{array}$ & $\begin{array}{l}\text { brown). } \\
\text { Lump sugar. }\end{array}$ \\
\hline
\end{tabular}


The prism was raised by the magner from $30^{\circ}$ to $60^{\circ}$, but the green glass, to which the magnetic needle attached itself with great difficulty, seemed to acquire repulsive rather than attractive powers by the same means. This was a specimen of fancy glass, of an apple-green colour, and cut to represent the calyx of a flower. I an ignorant as to what metal it owed its colour. It will be seen hereafter that the prism, which was of English fabric, exhibited an extraordinary affinity for all the metals, as well as for flint glass. The common green glass employed for wine bottles, and crown glass, notwithstanding the iron they contain, exhibited no striking attraction for the magnetic needle, which can be easily accounted for by remembering that the iron is in intimate combination with other bodies, and having its affinity employed, simulates neutrality.

The particular kind of porcelain used by dentists has very little attraction for the magnetic needle, and in other respects exceeds even the glasses in its affinity for non-ferruginous metals and gelatinous bodies. It and stone-ware are much alike.

The crystals of various kinds in this class, with the exception of protosulphate of iron, exhibit very low magnetic intensities for the needle, and confirm what $I$ have said about the common glasses. Carbonate of iron, it will be seen, has but little affinity for the magnet. Iceland spar is as difficult and capricious as flint in its attraction for the needle, but is remarkable in its affinity for non-ferruginous bodies. Talc has but little attraction for the magnet and zinc, but it is otherwise with iron and gold. It was not tried with other bodies. The specimen, which was remarkably thin, came from Delhi. The other substances were not measured, but the needle connected itself with them. Crystallized tin failed with the magnetic needle, but rose to $90^{\circ}$ after contact with the bar-magnet.

\section{5ith Class.}

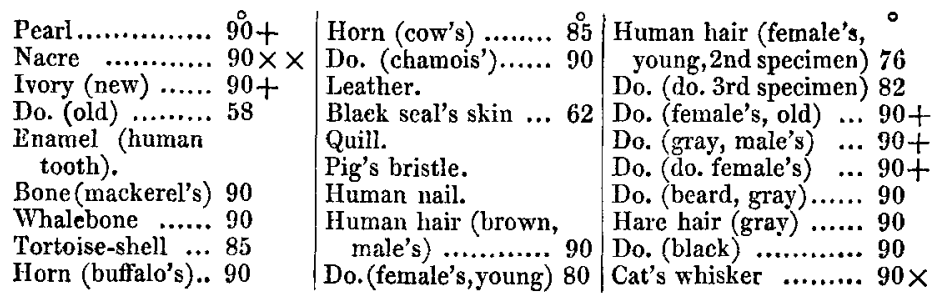


Amongst the animal products, pearl and mother-of-pearl are conspicuous in this class for their attraction for the magnetic needle, and for gold, copper, brass, lead, platinum, zinc, tin, and in all probability for the other metals, though they were not tried. Glass attracts it with equal facility. Horn of all kinds is extremely magnetic. The hair of the head has been already alluded to, and it must excite surprise that a body so fine could contain such high magnetic properties; and the fact is of extreme use as proving the very circumscribed extent of the spot, or rather of the point, which is connected with the needle in these experiments, for the very finest hair of the head that can be found exbibits as strong an affinity as the thickest of the same kind. Amongst hair the white whisker of a cat, of the mixed Angora breed, must not be omitted, as it was distinguished above all for its attractive properties which it maintained for all the substances with which it was tested.

6th Class.

\begin{tabular}{|c|c|c|}
\hline 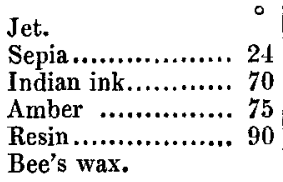 & $\begin{array}{l}\text { Spermaceti. } \\
\text { Composition candle. } \\
\text { Lac (pure) …......... } 35 \\
\text { Do. (red) ............ } 17 \\
\text { Do. (yellow). } \\
\text { Sealing-wax (red)...... } 36\end{array}$ & $\begin{array}{l}\text { Gas coal ... } \\
\text { Pit coal .... } \\
\text { Charcoal (o } \\
\text { Do. (box). }\end{array}$ \\
\hline
\end{tabular}

The substances of this class show no remarkable attraction for the magnetic needle, but this is not surprising when their nature is considered.

\section{7th Class.}

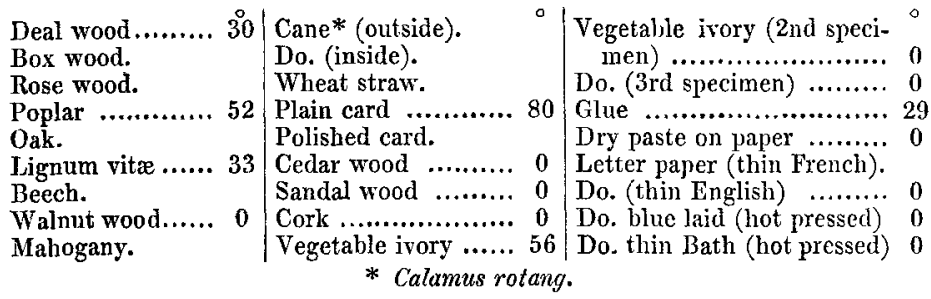

The woods, as might be expected, did not exhibit much attraction for the needle; but I shall have to speak of them again when I treat of the magnetism of non-ferruginous bodies, to which I now proceed.

[Continued at page 502.] 